\title{
Experimental Investigation of the Use of Expansive Materials to Increase Permeability in Coal Seams through Expansive Fracturing
}

\author{
Xiao Cui, ${ }^{1,2}$ Jiayong Zhang $\mathbb{D}^{1,2}$ Liwen Guo, ${ }^{1,2}$ and Xuemin Gong ${ }^{3}$ \\ ${ }^{1}$ College of Mining Engineering, North China University of Science and Technology, Tangshan, Hebei 063210, China \\ ${ }^{2}$ Mining Development and Safety Technology Key Lab of Hebei Province, Tangshan, Hebei 063210, China \\ ${ }^{3}$ College of Chemical Engineering, North China University of Science and Technology, Tangshan, Hebei 063210, China
}

Correspondence should be addressed to Jiayong Zhang; zjy815@ncst.edu.cn

Received 4 February 2020; Revised 16 June 2020; Accepted 10 July 2020; Published 31 July 2020

Academic Editor: Hongwei Yang

Copyright ( 12020 Xiao Cui et al. This is an open access article distributed under the Creative Commons Attribution License, which permits unrestricted use, distribution, and reproduction in any medium, provided the original work is properly cited.

Hydration reactions of expansive materials are typically very safe, easy to induce, and low in cost, while the crushing of such materials is typically free from noise, dust, vibration, and toxic gases. In the present study, to realize the application of expansive materials in the prevention of coal seam gas disasters, the microstructure, heat release rate, and expansive pressure of expansive materials were investigated for different degrees of hydration based on temperature and pressure measurements and using a scanning electron microscope (SEM); fracture characteristics were determined based on fracture tests of coal-like materials. The results show that the expansive material with $+30 \%$ water has the lowest hydration temperature $\left(100^{\circ} \mathrm{C}\right)$. The expansive pressure of the steel tube was found to reach $57 \mathrm{MPa}$, which is deemed suitable for application in coal seams. The strain and displacement of coal-like materials were found to increase with time, with four main cracks appearing. Based on these results, it is feasible that hydration reactions of expansive materials could increase both gas drainage and permeability in coal seams, thus reducing the risk of rock burst around boreholes in coal seams.

\section{Introduction}

The permeability of coal seams decreases with increasing coal seam depth, leading to simultaneous increases in gas content and pressure. Such processes result in considerable threat to production safety $[1,2]$. Drilling boreholes in lowpermeability coal seams typically results in the discharge of gas; previous studies have shown that optimizing the drilling position and enlarging the extracting radius can help to improve coal bed permeability $[3,4]$. Recent developments in pressure relief and permeability-increasing technology include hydraulic boreholes, hydraulic fracturing, intensive drilling, and concussion blasting $[5,6]$. However, these technologies have disadvantages: they are often labor intensive and require long construction periods and considerable financial investment. Therefore, investigating new pressure relief and permeability-increasing technology is important.
In the context considered here, expansive materials are gel-like cement materials that react with water and crystallize into the solid phase, resulting in an increase in their volume. The crystallization process exerts pressure on borehole walls, resulting in rock burst around the borehole when the expansive pressure and vertical tensile stress exceed the tensile strength of the surrounding brittle materials $[7,8]$. In an early study, expansive cement was produced by grinding ettringite and gypsum, calcining them at $1500^{\circ} \mathrm{C}$, and adding a proportion of finely ground slag [9]. A subsequent study increased the calcination temperature of calcium oxide and obtained an expansive material containing calcium sulfate and calcium oxide [10]. Expansive materials have also been developed by mixing calcium oxide and water in a borehole; this in situ hydration of quicklime was found to double the volume of material in the borehole, resulting in fracturing due to expansive pressure [11]. Efforts to develop expansive materials in China were initiated in the 
1950s. Early efforts investigated the sintering of high-aluminum cement with a rotary kiln and provided important guidance for future investigation of expansive materials [12], while a self-stressing silicate cement was developed successfully in 1957. A later study investigated the viability of using calcium oxide calcined at high temperature as an expansive source, based on analysis of the reaction mechanisms of the expansive material and on laboratory experiments and industrial testing, and developed an expansive crushing agent with a reaction pressure that can exceed $60 \mathrm{MPa}$ [13]. Expansive materials have been used widely in non-coal mining and construction blasting, and the technology is well developed. However, owing to the complexity of the coal seam environment, hydration reactions of expansive materials used in construction technology may cause some stability issues; thus, their use requires further optimization, and this technology has not yet been used in coal production.

Although the pressure in the borehole will decrease when the coal body breaks, as the hydration reaction continues, the volume of the expansive material can increase by more than 2 times, and the width and length of the cracks produced by the coal seam will continue to develop. The expansive pressure generated by the hydration reaction of the expansive material has a slower reaction speed and a uniform pressure increase to cause the cracked object, so the whole crushing process is noise-free, dust-free, and vibration-free. After the hydration reaction, it does not produce any toxic and harmful substances, which is a safe and reliable way of fracturing. The main features of the expansive fracturing were compared with those of other methods, as shown in Table 1.

Traditional borehole drilling technology is one of the most common methods adopted for use in coal seams with low gas permeability; drilling in this manner has been shown to increase the exposed area and pressure release range of boreholes, thus both increasing gas drainage and reducing gas pressure. Here, a new technology that increases the permeability of coal seams is proposed; this method adopts recent advances in borehole technology and expansive materials rather than relying on traditional methods. According to existing knowledge regarding borehole gas drainage, the expansion of boreholes in coal seams can be achieved using either perfusive materials or expansive materials; the nature of this expansion depends on the expansive pressure exerted by drilling in the vicinity of coal fractures and on the physical and chemical changes that affect the gas state. The ability to increase coal seam permeability using these techniques could help address gas drainage issues associated with mining processes. Therefore, the production of an expansive material for use in coal seams would be of great theoretical and practical significance for coal mine production safety, gas resource development, and environmental protection.

\section{Materials and Methodology}

2.1. Materials. The expansive materials were calcined at temperatures of $1350-1500^{\circ} \mathrm{C}$ and comprised primarily the following components (in order of decreasing percentage content): calcium oxide (f-CaO), tricalcium silicate $\left(\mathrm{C}_{3} \mathrm{~S}\right)$, tetracalcium aluminoferrite $\left(\mathrm{C}_{4} \mathrm{AF}\right)$, and tricalcium aluminate $\left(\mathrm{C}_{3} \mathrm{~A}\right)$. Based on mass balance calculations, calcium oxide reacts with silicon dioxide $\left(\mathrm{SiO}_{2}\right)$, aluminum oxide $\left(\mathrm{Al}_{2} \mathrm{O}_{3}\right)$, and ferric oxide $\left(\mathrm{Fe}_{2} \mathrm{O}_{3}\right)$, producing tricalcium silicate $\left(\mathrm{C}_{3} \mathrm{~S}\right)$, tetracalcium aluminoferrite $\left(\mathrm{C}_{4} \mathrm{AF}\right)$, and tricalcium aluminate $\left(\mathrm{C}_{3} \mathrm{~A}\right)$, and transforms the remaining calcium oxide to $\mathrm{f}-\mathrm{CaO}$. The components of the expansive materials are presented in Table 2.

2.2. Reaction Temperature Measurement. Owing to the complexity of the coal seam environment and to ensure production safety, accurate reaction parameters must be recorded for expansive materials used in coal seams. In particular, reaction temperature and reaction rate are important factors determining the effects of expansive materials.

The use of expansive materials in coal seam drilling to induce expansive fracturing can result in exothermic hydration reactions and increase the volume of calcium oxide $(\mathrm{CaO})[11,14,15]$, magnesium oxide $(\mathrm{MgO})$, and anhydrous calcium sulfoaluminate $\left(3 \mathrm{CaO} \cdot \mathrm{Al}_{2} \mathrm{O}_{3}\right)$ $[16,17]$. The main hydration reactions for the expansive material are as follows:

$$
\begin{aligned}
\mathrm{CaO}+\mathrm{H}_{2} \mathrm{O} & \longrightarrow \mathrm{Ca}(\mathrm{OH})_{2}+H \uparrow \\
\mathrm{MgO}+\mathrm{H}_{2} \mathrm{O} & \longrightarrow \mathrm{Mg}(\mathrm{OH})_{2}+H \uparrow \\
3 \mathrm{CaO} \cdot \mathrm{Al}_{2} \mathrm{O}_{3}+3 \mathrm{CaSO}_{4}+32 \mathrm{H}_{2} \mathrm{O} & \longrightarrow 3 \mathrm{CaO} \cdot \mathrm{Al}_{2} \mathrm{O}_{3} \cdot 3 \mathrm{CaSO}_{4} \cdot 32 \mathrm{H}_{2} 0+H \uparrow
\end{aligned}
$$

Physical parameters of each compound are shown in Table 3. Calcium oxide $(\mathrm{CaO})$ reacts with water to produce calcium hydroxide $\left(\mathrm{Ca}(\mathrm{OH})_{2}\right)$. Magnesium oxide $(\mathrm{MgO})$ reacts with water to produce magnesium hydroxide $\left(\mathrm{Mg}(\mathrm{OH})_{2}\right)$; calcium sulfate $\left(\mathrm{CaSO}_{4}\right)$ and anhydrous calcium sulfoaluminate $\left(3 \mathrm{CaO} \cdot \mathrm{Al}_{2} \mathrm{O}_{3}\right)$ react with water to produce calcium sulfoaluminate hydrates $\left(3 \mathrm{CaO} \cdot \mathrm{Al}_{2} \mathrm{O}_{3} \cdot 3 \mathrm{CaSO}_{4} \cdot 32 \mathrm{H}_{2} \mathrm{O}\right)$. The solid volume growth rate after hydration is as follows [13]:

$$
\begin{aligned}
\Delta V_{\mathrm{CaO}} & =\frac{33.18-16.79}{16.79} \times 100 \%=97 \%, \\
\Delta V_{\mathrm{MgO}} & =\frac{24.71-11.26}{11.26} \times 100 \%=119 \%, \\
\Delta V_{\mathrm{CA}} & =\frac{725-371}{371} \times 100 \%=95 \%
\end{aligned}
$$

The device used to test reaction temperature is shown in Figure 1. Temperature tests were conducted under ambient temperature conditions $\left(\sim 20^{\circ} \mathrm{C}\right)$. A sealing and heat preservation device (volume $1 \mathrm{~L}$ ) was adopted, a Pt100 temperature sensor (measurement range $0-200^{\circ} \mathrm{C}$ ) was connected, and the MK-200E paperless recorder was used to monitor data. A balance (accurate to $0.01 \mathrm{~g}$ ) was used to weigh out $500 \mathrm{~g}$ of the expansive material; then, the material was stirred evenly with varying proportions of water before being added to the insulation device. Changes in reaction temperature over time were recorded. 
TABle 1: Comparison of expansive fracturing with other methods of permeability improvement.

\begin{tabular}{|c|c|c|c|}
\hline Method & Principle & Advantage & Limitation \\
\hline $\begin{array}{l}\text { Expansive } \\
\text { fracturing }\end{array}$ & $\begin{array}{l}\text { Solid expansion and } \\
\text { exothermic desorption }\end{array}$ & $\begin{array}{l}\text { Noise-free, dust-free, and } \\
\text { vibration-free }\end{array}$ & Reaction exotherm \\
\hline $\begin{array}{l}\text { Concussion } \\
\text { blasting }\end{array}$ & Gas volume expansion & $\begin{array}{l}\text { Quick reaction and } \\
\text { obvious effect }\end{array}$ & $\begin{array}{c}\text { Vibration, noise, flying stone, toxic gas, and easy to induce } \\
\text { gas outburst }\end{array}$ \\
\hline Drilling & Pressurization-discharging & Traditional technology & $\begin{array}{c}\text { Large amount of work, long construction period, and rapid } \\
\text { drilling-induced coal and gas outburst }\end{array}$ \\
\hline Hydraulic method & $\begin{array}{l}\text { Liquid punching, } \\
\text { fracturing, and } \\
\text { displacement }\end{array}$ & $\begin{array}{l}\text { The coal is adequately } \\
\text { relieved of pressure }\end{array}$ & $\begin{array}{l}\text { Fracture development has no direction and the process is } \\
\text { complex }\end{array}$ \\
\hline $\begin{array}{l}\mathrm{CO}_{2} \text { phase change } \\
\text { fracturing }\end{array}$ & $\begin{array}{l}\text { Gas volume expansion and } \\
\text { displacement }\end{array}$ & $\begin{array}{l}\text { Gas can be replaced to } \\
\text { improve the recovery rate }\end{array}$ & $\begin{array}{l}\text { The coal body with complex device, high sealing } \\
\text { requirement of borehole and excessive crushing is easy to } \\
\text { lead to pore blockage }\end{array}$ \\
\hline
\end{tabular}

TABLE 2: Components of expansive materials.

\begin{tabular}{lcccccccc}
\hline & \multicolumn{9}{c}{ Chemical composition (\%) } & & & & Liter weight (g/L) \\
LOI (loss on ignition) & $\mathrm{SiO}_{2}$ & $\mathrm{Al}_{2} \mathrm{O}_{3}$ & $\mathrm{Fe}_{2} \mathrm{O}_{3}$ & $\mathrm{CaO}$ & $\mathrm{MgO}$ & $\mathrm{f}-\mathrm{CaO}$ & $\sum$ & 99.75 \\
\hline 0.62 & 5.41 & 1.10 & 2.60 & 89.10 & 0.92 & 73.26 & 1320 \\
\hline
\end{tabular}

TABle 3: Physical parameters of each compound.

\begin{tabular}{|c|c|c|c|c|c|c|c|}
\hline & $\mathrm{CaO}$ & $\mathrm{MgO}$ & $\mathrm{CaO} \cdot \mathrm{Al}_{2} \mathrm{O}_{3}$ & $\mathrm{CaSO}_{4}$ & $\mathrm{Ca}(\mathrm{OH})_{2}$ & $\mathrm{Mg}(\mathrm{OH})_{2}$ & $\mathrm{H}_{2} \mathrm{O}$ \\
\hline Molecular weight (g) & 56.08 & 40.30 & 101.96 & 172.17 & 74.08 & 58.32 & 18.02 \\
\hline Apparent density $\left(\mathrm{g} / \mathrm{cm}^{3}\right)$ & 3.34 & 3.58 & 3.90 & 2.61 & 2.24 & 2.36 & 1.00 \\
\hline Gram-molecular volume $\left(\mathrm{cm}^{3}\right)$ & 16.79 & 11.26 & 26.14 & 65.97 & 33.08 & 24.71 & 18.02 \\
\hline
\end{tabular}

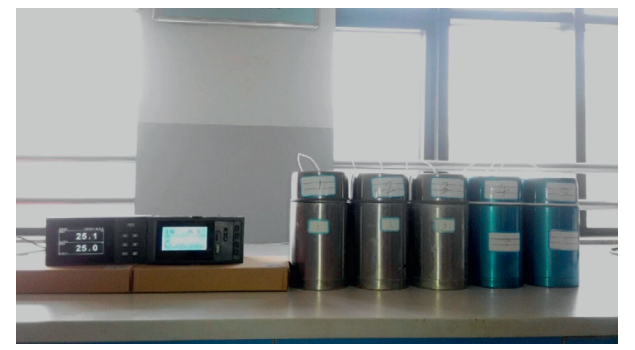

Figure 1: Device used to test reaction temperature.

2.3. Expansive Pressure Measurement. The measurement of expansion pressure is made using thick-walled round steel tubes based on Building Materials Industry Standard of China (JC 506-1992). The basic principles underlying expansive pressure testing of expansive materials are as follows. The expansive material is poured into a thickwalled circular steel tube; when the expansive material in the tube undergoes a hydration reaction and expands in volume [18], the material will exert strain on the tube wall. This causes the tube to expand. The expansive pressure acting on the inner wall of the tube can be described by the thick-wall cylinder theory of elastic mechanics $[19,20]$. The radial compressive stress and tangential tensile stress of the thick-walled tube under expansive pressure are as follows:

$$
\begin{gathered}
\sigma_{r}=\left(P_{\mathrm{ex}}-P_{0}\right) \frac{R_{i}^{2}}{R_{e}^{2}-R_{i}^{2}}\left[1-\frac{R_{e}^{2}}{r^{2}}\right], \\
\sigma_{\theta}=\left(P_{\mathrm{ex}}-P_{0}\right) \frac{R_{i}^{2}}{R_{e}^{2}-R_{i}^{2}}\left[1+\frac{R_{e}^{2}}{r^{2}}\right],
\end{gathered}
$$

where $\sigma_{r}$ and $\sigma_{\theta}$ are the radial compressive stress and tangential tensile stress, respectively, and $P_{\text {ex }}$ and $P_{0}$ are the internal expansive and external pressures, respectively. Under the test conditions considered here, the steel tube is not subject to external pressures, such that $P_{0}=0 . R_{i}$ and $R_{e}$ represent the internal radius and external radius, respectively, and $r$ is the radial distance from the center to the cylinder. When $r=R_{e}$, equations (3) and (4) can be modified as follows:

$$
\sigma_{\theta}=\frac{2 P_{\mathrm{ex}} R_{i}^{2}}{R_{e}^{2}-R_{i}^{2}}
$$

According to the theory of elasticity, the tangential strain of a steel tube under radial and tangential stress is as follows:

$$
\varepsilon_{\theta}=\frac{\sigma_{\theta}-v \sigma_{r}}{E}=\frac{2 P_{\mathrm{ex}} R_{i}^{2}}{E\left(R_{e}^{2}-R_{i}^{2}\right)},
$$

where $E$ is the elastic modulus of the steel tube. Then, the expansive pressure can be expressed as follows: 


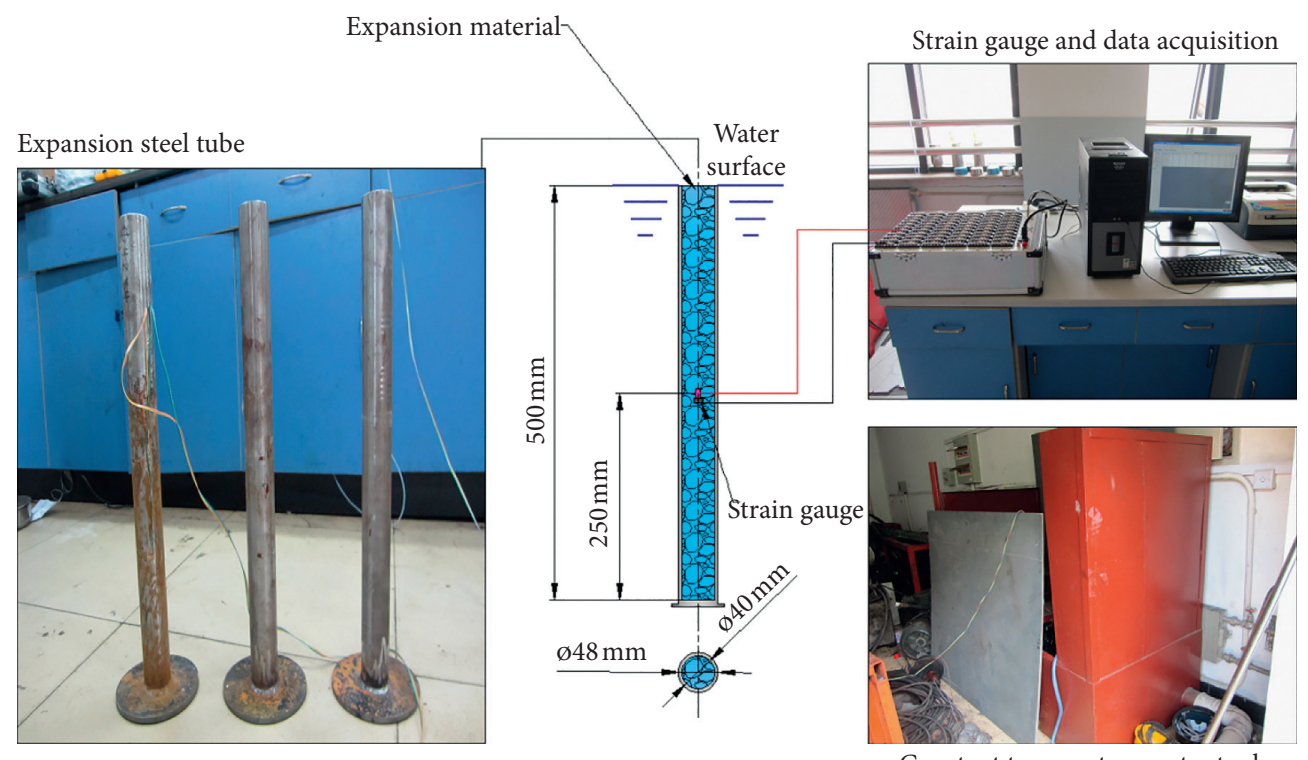

Figure 2: Determination of expansive pressure.

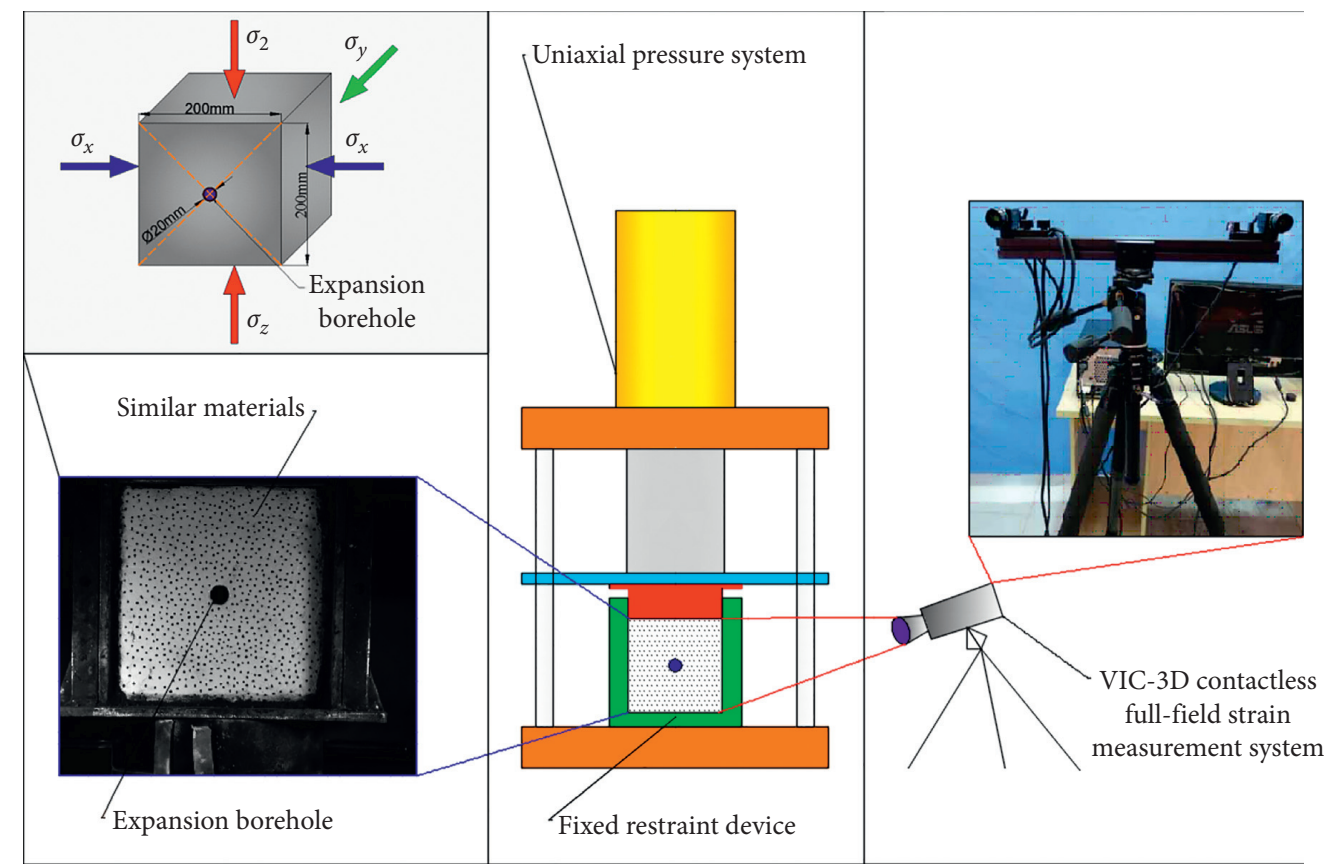

FIgURE 3: Experimental setup used to analyze fracturing of the expansive material.

$$
\mathrm{P}_{\mathrm{ex}}=\frac{\varepsilon_{\theta} E\left(R_{e}^{2}-R_{i}^{2}\right)}{2 R_{i}^{2}} .
$$

In this test, a Q235 cold-processed steel tube was used, with an elastic modulus of $200.06 \mathrm{GPa}$ and an inner radius, outer radius, and length of $20 \mathrm{~mm}, 24 \mathrm{~mm}$, and $500 \mathrm{~mm}$, respectively [21]. One end of the steel tube was sealed by welding with a thick steel plate. The resistance strain gauge was glued to the adhesive strain gauge at the midpoint of the steel tube, $250 \mathrm{~mm}$ from the base of the tube. The strain gauge used was model BX120-20AA. The leading end of the resistance strain gauge was connected to the strain gauge by a double-stranded wire $[21,22]$, and the steel tube was placed in a water bath with a constant temperature of $25^{\circ} \mathrm{C}$. The device used to test expansive pressure is shown in Figure 2.

\subsection{Microstructural Analysis of Expansive Material Using} SEM. To further analyze the expansive pressure generated by the expansive material and investigate the structural changes and mechanical properties of the material, its microstructure before and after the hydration reaction was 
studied using the JSM-IT100 scanning electron microscope (SEM) $[23,24]$. Double-sided tape was pasted on the load tray to maintain a dry environment, and small samples of the expansive material were placed on the tape to ensure uniform distribution. Metal film was sprayed on the surface of the sample before the microstructural morphology of the expansive material was observed. The hydration reaction was induced by adding $+30 \%$ water for $24 \mathrm{~h}$; then, a specimen of the expansive material was observed to identify any changes in crystal structure following hydration.

\subsection{Fracture Analysis of Expansive Material}

2.5.1. Preparation of Coal-Like Materials. The compressive strengths of materials can be used as an index to measure their similarity to raw coal. Cement and gypsum were used to produce a material with similar strength to coal. The ratios of pulverized coal to cement, gypsum, and water in this material were determined to be $0.5: 0.25: 0.05: 0.2$ based on the results of uniaxial testing undertaken in previous studies [25]. This mixture was stirred evenly and placed into a selfmade cube mold with dimensions of $200 \times 200 \times 200 \mathrm{~mm}$; the mold was left to stand for 9-10 h to allow demodulation and was maintained at constant temperature in a drying oven for one week. Then, the center of the coal-like material was drilled using a coring drill with diameter of $20 \mathrm{~mm}$.

2.5.2. VIC-3D System for Strain Measurement. The surface displacement and strain distribution of the coal-like material under expansive pressure and uniaxial stress were calculated by comparing image correlation points with the VIC-3D contactless full-field strain measurement system. This system requires only two image collectors. The surface of the tested material was coated with a random black and white pattern. During the deformation of the sample, the movement of individual pixels was recorded and translated into a vector; in this manner, the strain data before and after deformation can be determined based on a vector field generated by the surface deformation of the material. The coal-like material and the experimental setup used to analyze fracturing of the expansive material are shown in Figure 3. Coal seams are under static isotropic pressure due to the overlying and surrounding rocks, and this pressure increases with depth of a coal seam within the rock mass. Here, the distribution of coal seam stress was optimized by setting the boundary conditions in the $x,-x$, and $-y$ directions as fixed constraints, with the in situ stress $\sigma_{z}=5 \mathrm{MPa}$. The $y$ direction indicates distance along the mining section, with the $y$ axis set as the free surface.

\section{Results and Discussion}

3.1. Reaction Temperature. Temperature is one of the primary factors influencing the performance of the expansive material: when temperature is higher, the hydration rate of the expansive material is faster and the expansion pressure exerted is higher. Moreover, the response of expansive materials with different proportions of water added for the

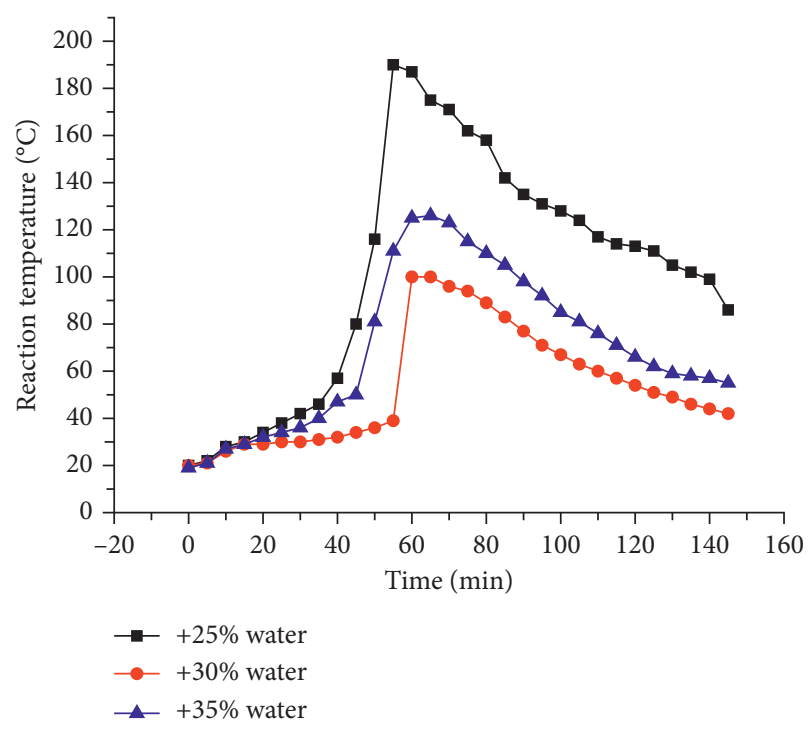

Figure 4: Variation in reaction temperature with time.

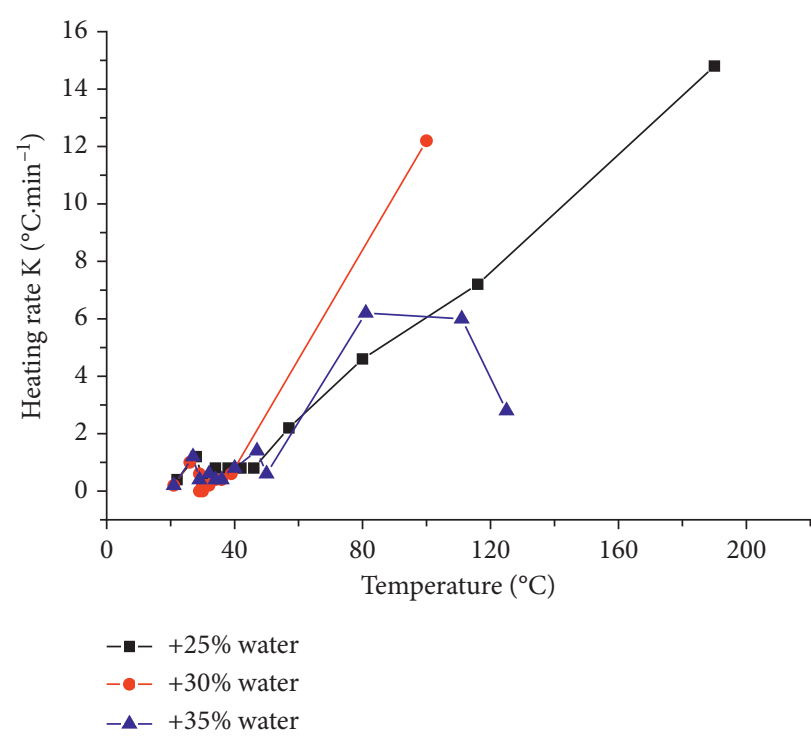

FIgURe 5: Heating rate curve for the expansive material.

hydration reaction $(25 \%, 30 \%$, and $35 \%)$ will vary depending on temperature. Reaction temperatures were measured during the laboratory experiments, as shown in Figure 4 . The results show that changes in reaction temperature can be controlled effectively by controlling the water-cement ratio.

Changes in reaction temperature for expansive materials with different water-cement ratios can be summarized as follows. Initially, reaction temperature increases slowly over the range $20-40^{\circ} \mathrm{C}$; when the temperature reaches $40^{\circ} \mathrm{C}$, the reaction speeds up and there is a marked increase in temperature. Subsequently, reaction temperature peaks before declining slowly. These results demonstrate that temperature changes during the hydration reaction of the expansive material exhibit the same form regardless of water content. The maximum reaction temperatures reached for the $+25 \%$, 


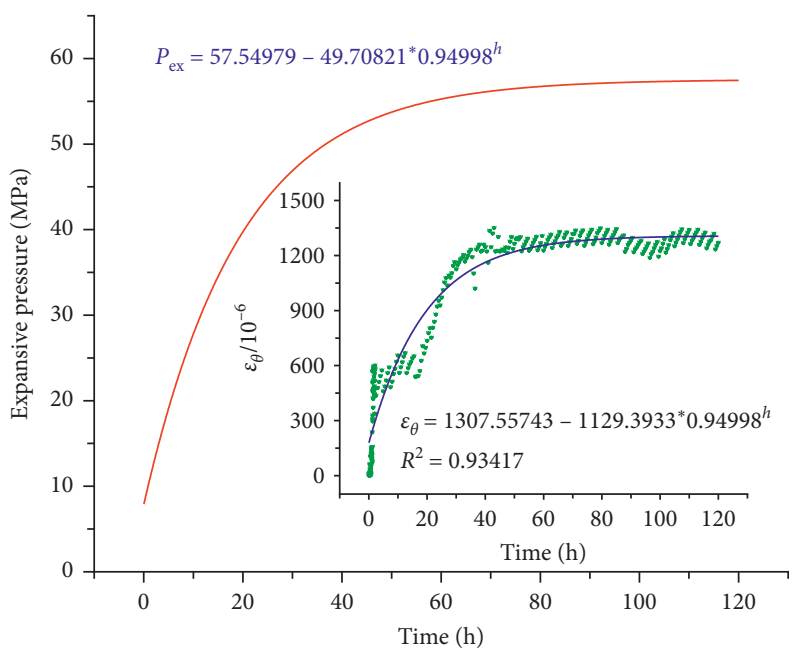

FIgURE 6: Changes in tangential strain for steel tube and expansive pressure of expansive material over time.

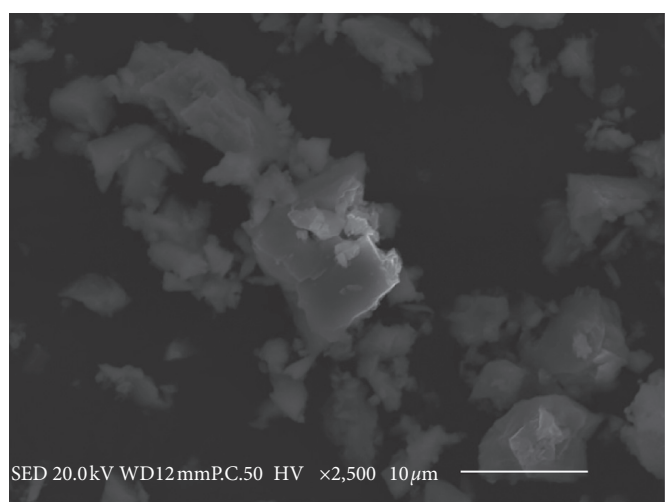

(a)

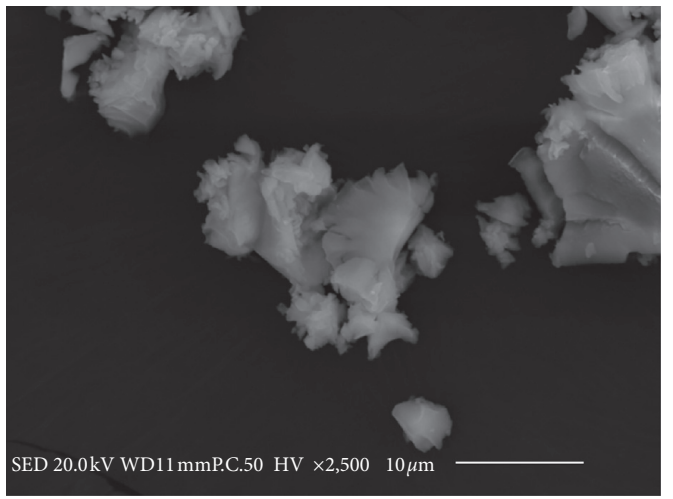

(c)

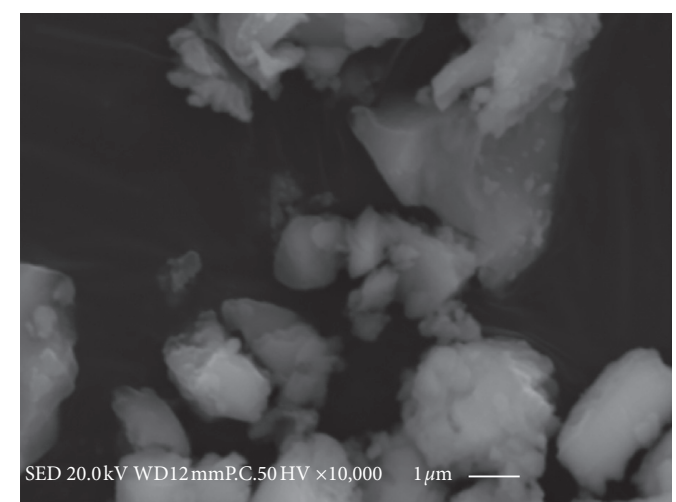

(b)

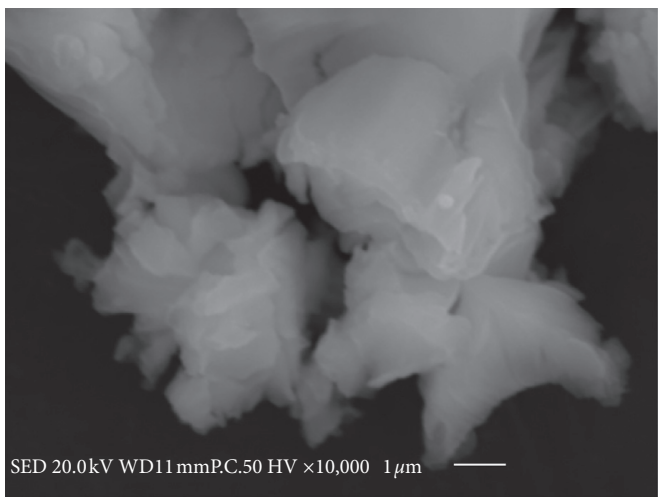

(d)

FIGURE 7: SEM images for expansive material. (a) Sample before hydration at 2,500x. (b) Sample before hydration at 10,000x. (c) Sample after hydration at 2,500x. (d) Sample after hydration at 10,000x.

$+30 \%$, and $+35 \%$ mixtures were $190^{\circ} \mathrm{C}, 100^{\circ} \mathrm{C}$, and $126^{\circ} \mathrm{C}$, respectively; these temperatures were reached at 55,60 , and $65 \mathrm{~min}$, respectively. These results demonstrate that the time required for the expansive material to reach the maximum reaction temperature increases with increasing water-cement ratio. However, the maximum reaction temperature was found to decrease considerably with increasing water content between $+25 \%$ and $+35 \%$.
The temperature of the expansive material was measured every $5 \mathrm{~min}$ for each mixture and the temperature dependence of the heating rate $\mathrm{K}$ was investigated. This parameter is considered to represent the rate of change of reaction temperature for the expansive material, where $K=\Delta \mathrm{T} / 5$.

The heating rate curve for the expansive material with $+25 \%,+30 \%$, and $+35 \%$ water is presented in Figure 5 ; this curve was developed based on fitting of the temperature 

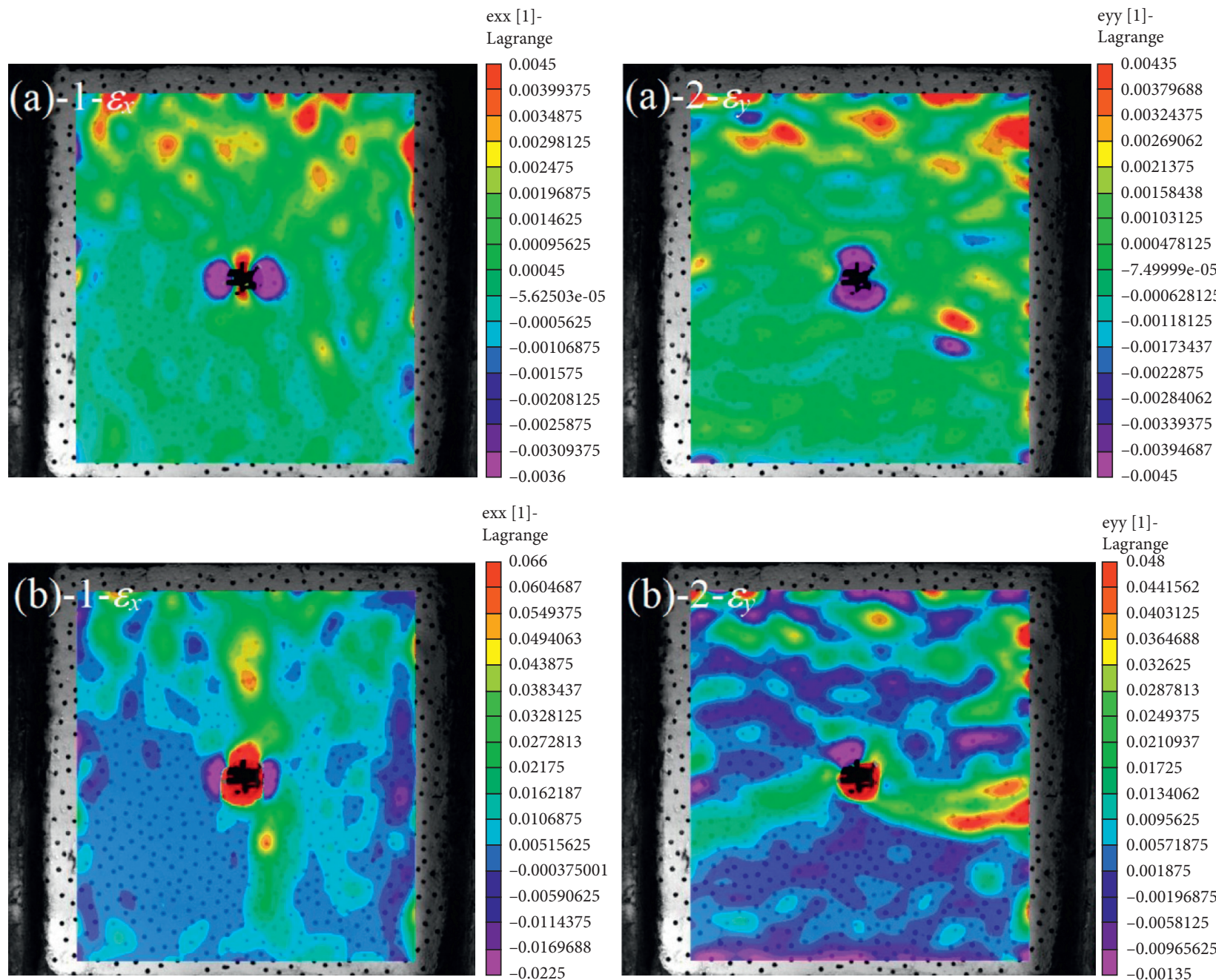

exx [1]-
Lagrange
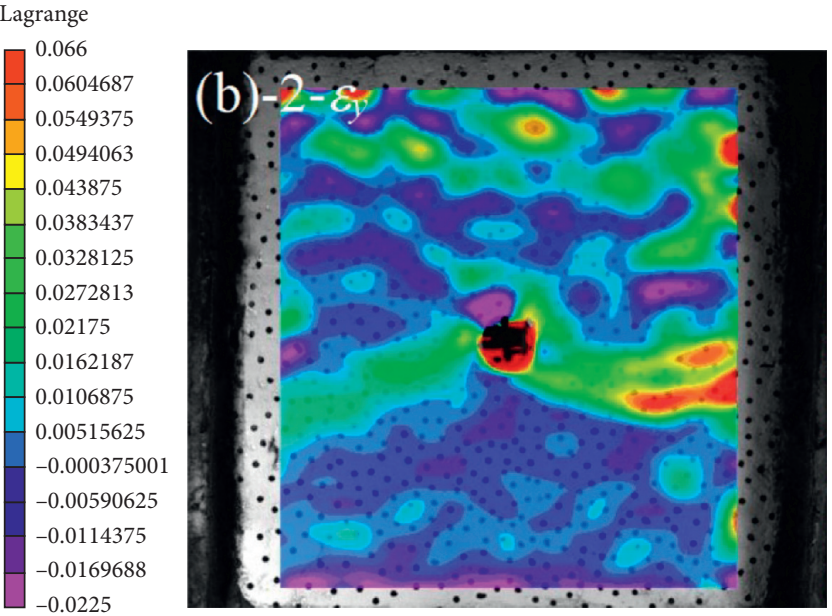

eyy [1]-

Lagrange

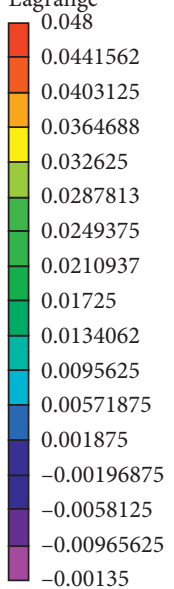

\section{exx [1]-
Lagrange}
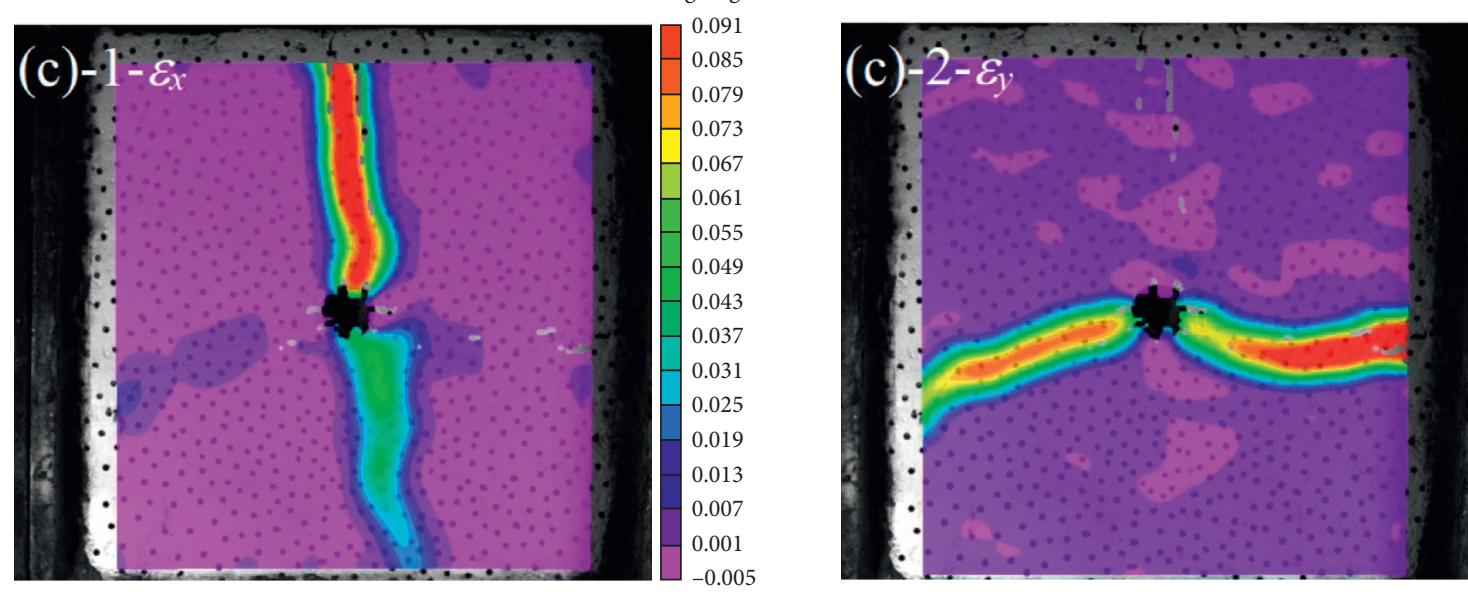

eyy [1]-

Lagrange

0.076
0.0709062
0.0658125
0.0607187
0.055625
0.0505312
0.0454375
0.0403437
0.03525
0.0301562
0.0250625
0.0199687
0.014875
0.00978125
0.0046875
-0.00040625
-0.0055

FIGURE 8: Variation in strain response for coal-like materials with reaction time similar to the expansive material considered here. (a)-1 Hydration reaction time $3 \mathrm{~h}$ ( $x$ direction strain). (a)-2 Hydration reaction time $3 \mathrm{~h}$ ( $y$ direction strain). (b)-1 Hydration reaction time $6 \mathrm{~h}$ ( $x$ direction strain). (b)-2 Hydration reaction time $6 \mathrm{~h}$ ( $y$ direction strain). (c)-1 Hydration reaction time $10 \mathrm{~h}$ ( $x$ direction strain). (c)-2 Hydration reaction time $10 \mathrm{~h}$ ( $y$ direction strain).

change curve in Figure 4. These results demonstrate that when the reaction temperature of the expansive material is less than $40^{\circ} \mathrm{C}$, the heating rate is slow and is effectively the same for all three types of expansive material. Conversely, when the reaction temperature exceeds $40^{\circ} \mathrm{C}$, the heating rate increases rapidly for all three types, although heating 
occurs much more rapidly for the material with $+30 \%$ and $+35 \%$ water than for the material with $+25 \%$ water. This occurs because the heat of hydration reactions is released more rapidly with increasing moisture content; more complete reaction of the expansive material also occurs with increasing moisture content. However, when the moisture content is very high and the reaction temperature reaches $100^{\circ} \mathrm{C}$ (i.e., the boiling point of water), the water begins to evaporate, resulting in a reduction in the rate of heating. Conversely, when the moisture content is low, the influence of water on the expansive material leads to a continuous increase in the heating rate. Here, the maximum temperature reached for the expansive material with $+30 \%$ water was $100^{\circ} \mathrm{C}$; accordingly, it can be assumed that complete hydration of the expansive material occurred and that the moisture content effectively controlled the reaction temperature.

3.2. Expansive Pressure. Measurement of the expansive pressure of the expansive material based on tangential strain exerted on a thick-walled circular steel tube is presented here. Through the test of variation in reaction temperature with time, it is determined that the expansive material under the condition of $+30 \%$ water is most suitable for coal seam, so only the expansive pressure under this specific condition is measured. Changes in tangential strain and expansive pressure with time are illustrated in Figure 6.

The test was conducted in a water bath with a constant temperature of $25^{\circ} \mathrm{C}$. Initially, the reaction rate of the expansive material was rapid; this accelerated reaction increased the tangential strain significantly. As the test progressed, the reaction slowed down gradually, resulting in small changes in strain. However, as the expansive material was not fully developed when the reaction rate slowed, the tangential strain continued to increase slowly. Accordingly, the measured strain did not reach a stable level until $\sim 120 \mathrm{~h}$ after the reaction was initiated. As the strain gauge used here is relatively sensitive, variation in strain with time $(h)$ was further analyzed and fitted according to the following relationship:

$$
\varepsilon_{\theta}=1307.55743-1129.3933 \times 0.94998^{h} .
$$

The expansive pressure can be obtained based on the strain acting on the steel tube as described in equation (4). As shown in Figure 6, comparative analysis has shown that expansive pressure varies with time in a manner similar to strain; in fact, the expansive pressure of the expansive material increases with time to a maximum of $57 \mathrm{MPa}$. These results suggest that the expansive pressure generated by the hydration reaction of the expansive material can be utilized to fracture coal seams by drilling.

3.3. Microstructural Analysis Using SEM. SEM micrographs of the expansive material before and after hydration are shown in Figure 7 and demonstrate clearly that hydration changes the microstructure and density of the expansive

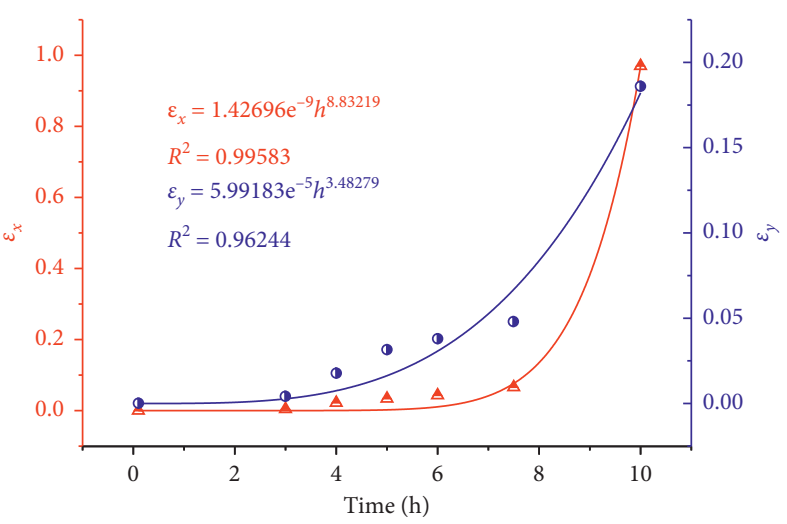

FIgURE 9: Variation in maximum stress variables with time in the $x$ and $y$ directions.

material. As shown in Figures 7(a) and 7(b), the expansive material was composed of particles with smooth, dense, and nonporous surfaces before hydration; the apparent density of these particles was relatively high. The main component of the expansive material is calcium oxide. Small and dispersed particles of calcium oxide facilitate hydration, forming calcium hydroxide crystal centers and a large number of fine crystals. As shown in Figures $7(\mathrm{c})$ and $7(\mathrm{~d})$, the particle surfaces following hydration are relatively rough and microcracks and nanocracks are relatively well dispersed, forming many small voids and increasing porosity, although the volume of the hydrated particles is twice that of the original particles. These results demonstrate that changes in expansive pressure are a result of changes in crystal structure during hydration.

\subsection{Analysis of Borehole Expansive Fracturing. Images taken} by the VIC-3D contactless full-field strain measurement system can be used to explain the development of strain over time when expansive materials are used to fracture coal-like materials. Changes in the expansive pressure occur with increasing hydration time; this is reflected in changes in the mechanical properties of the expansive material. Changes in strain response for the materials with similar reaction times to the expansive material used here are shown in Figure 8.

In Figure 8, high-strain regions are shown in red and low-strain regions are shown in blue. For the coal-like materials, it is clear that, under uniaxial stress, the failure mechanism develops from widely distributed strain to highly localized strain with increasing hydration time. The wider distribution of strain results partly from the expansive pressure of the material after hydration and partly from the action of in situ stress. The figure also shows the fracture characteristics of the coal-like materials with fixed constraints; these conditions replicate the crushing mechanism that acts during the fracture process as a result of holes being drilled in the surrounding area during the reaction of expansive materials. With increasing hydration reaction time, the fracture effect is gradually increased. Fitting analysis was performed on the maximum stress variables at different times in the $x$ and $y$ directions; the results are presented in 
$U(\mathrm{~mm})$
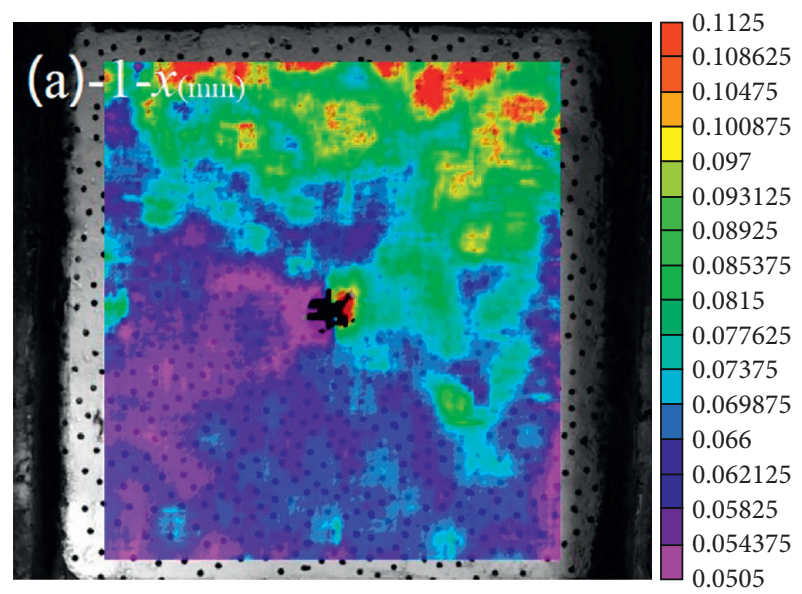

$U(\mathrm{~mm})$

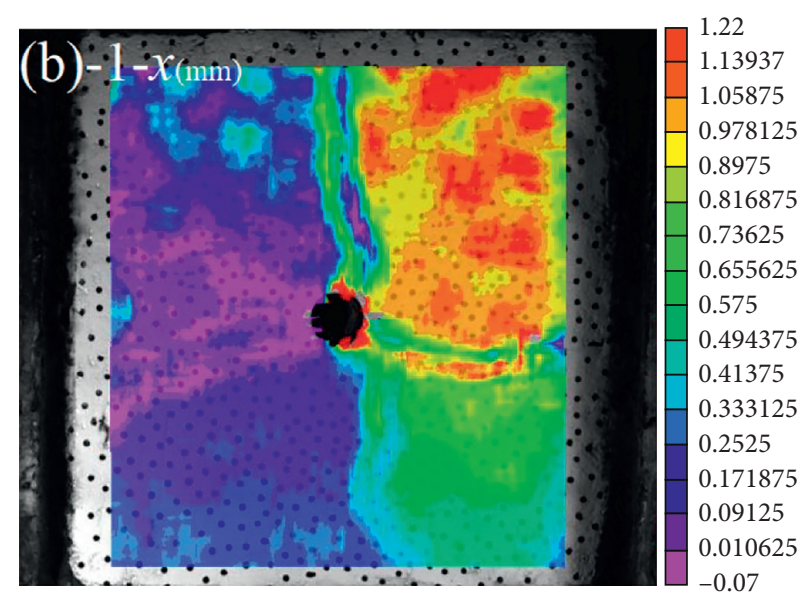

$U(\mathrm{~mm})$
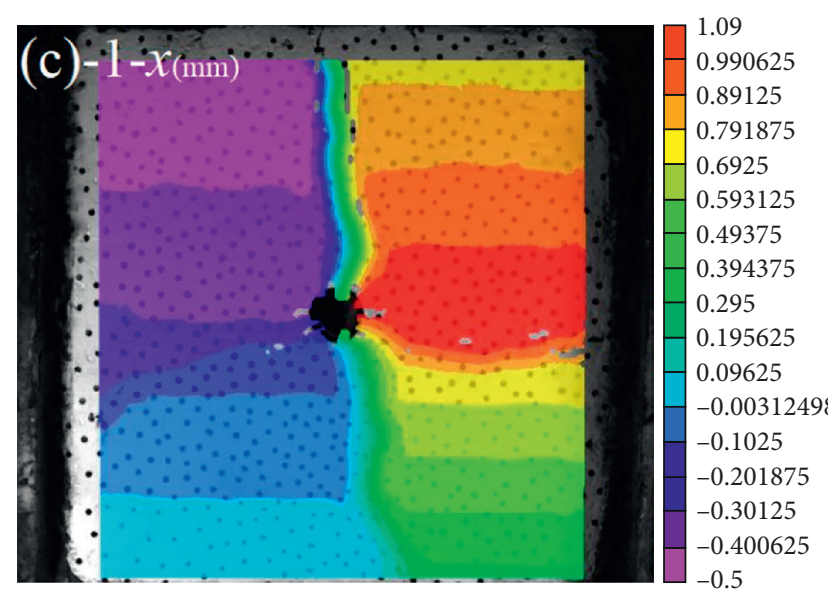

$V(\mathrm{~mm})$

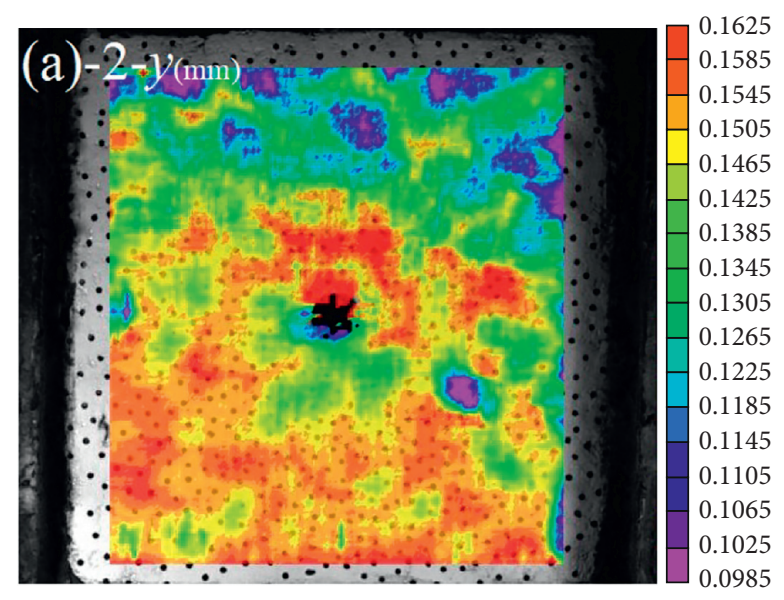

$V(\mathrm{~mm})$

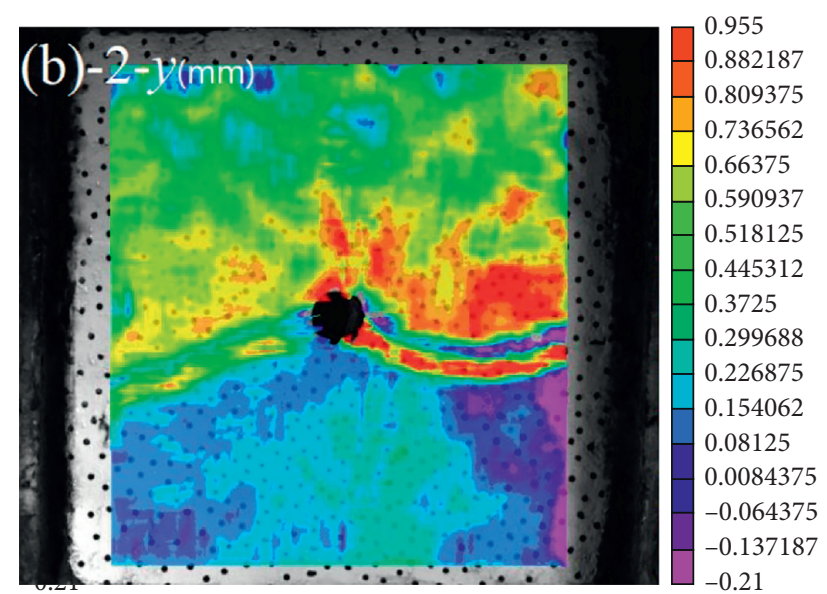

$V(\mathrm{~mm})$

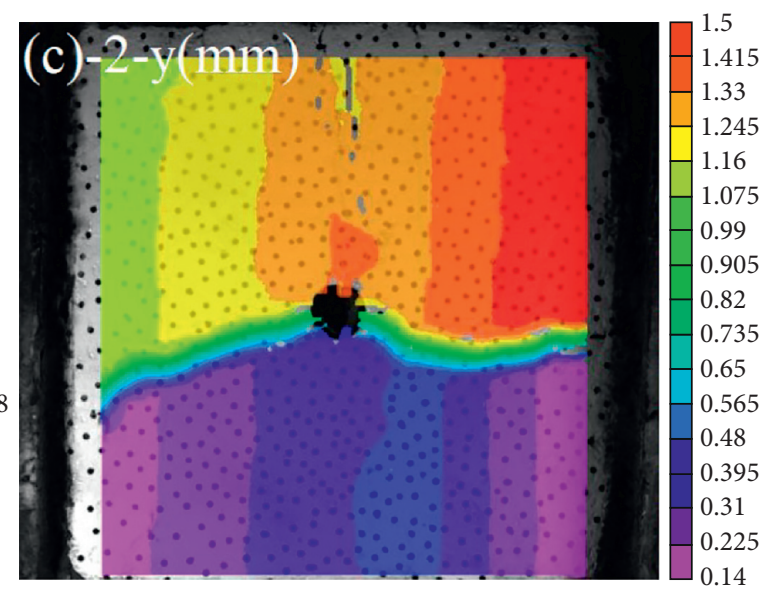

FIGURE 10: Variation in displacement of coal-like materials with reaction time of the expansive material. (a)-1 Hydration reaction time $3 \mathrm{~h}$ ( $x$ direction displacement). (a)-2 Hydration reaction time $3 \mathrm{~h}$ ( $y$ direction displacement). (b)-1 Hydration reaction time $6 \mathrm{~h}$ ( $x$ direction displacement). (b)-2 Hydration reaction time $6 \mathrm{~h}$ ( $y$ direction displacement). (c)-1 Hydration reaction time $10 \mathrm{~h}$ ( $x$ direction displacement). (c)-2 Hydration reaction time $10 \mathrm{~h}$ ( $y$ direction displacement).

Figure 9. The strain was found to increase significantly after a reaction time of $6 \mathrm{~h}$, indicating that the coal-like material fractured; this can be considered to represent the formation of a gas migration channel in a coal seam.
Further analysis was conducted for the coal-like materials in the form of a displacement test (Figure 10). The number of macroscopic cracks on the surface of the coal-like material increased to 4 , and cracks started to form in the 


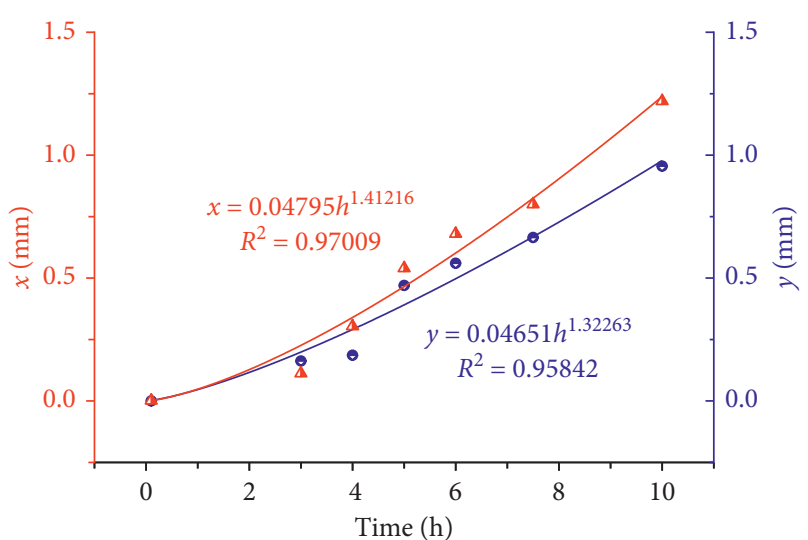

Figure 11: Changes in maximum displacement with time in the $x$ and $y$ directions.

outer wall of the expansion borehole and penetrate the entire specimen. In the expansive material, thermal stress was the dominant controlling factor at the start of the reaction, forming a temperature gradient around the borehole; this contributed to changes in the physical and mechanical properties of material in this area. In particular, elevated temperature resulted in thermal expansion and increases in in situ stress, focusing stress along the coal specimen boundary and forming fractures in the damaged area. As the reaction progressed, the expansive stress became the dominant controlling factor. Meanwhile, the constraint imposed by the borehole wall of the coal specimen was higher than that of the boundary. Under the action of the expansive force, cracks began to form in the damaged strip along the boundary, and these cracks expanded from the borehole to the boundary until the coal-like materials were connected. Changes in fracture displacement with time are shown in Figure 11. Four main cracks were generated during the test; the length and width of these cracks increased with the reaction time of the expansive material.

\section{Conclusion}

Based on a combination of theoretical research, basic testing, and fracture testing, the response characteristics of an expansive material and its effect on fracturing of coal-like materials have been studied. The following conclusions can be drawn.

Measurement of the basic parameters of the expansive material indicated that the hydration temperature of the expansive material was lowest $\left(100^{\circ} \mathrm{C}\right)$ when $+30 \%$ water was used. After the expansive material had reacted fully, it continued to exert pressure on the wall of the steel tube, controlling the expansive pressure effectively at $57 \mathrm{MPa}$.

Based on investigation of the mechanical properties and structural characteristics of coal, expansive fracture testing was conducted on materials with reaction times similar to that of the expansive material. Four main cracks were generated by fracturing of the test block.

Coal seam fracturing based on expansive materials is known to be safe, easy to undertake, low in cost, noise-free, dust-free, vibration-free, and free from toxic gas products. This study represents an initial feasibility study for the practical application of this technology. The process of expansion is known to increase damage and exploit inherent weaknesses in coal seams. However, the slow development of fractures can ensure stability of the coal roof, effectively preventing coal and gas outburst, and may be suitable for application in gas prevention and control for low-permeability coal seams. Such application could greatly reduce construction quantity and operation time. Application of this new coal seam fracturing technology based on expansive materials may prove to be feasible in practice and merits further investigation.

\section{Data Availability}

The data used to support the findings of this study are available from the corresponding author upon request.

\section{Conflicts of Interest}

The authors declare that they have no conflicts of interest.

\section{Acknowledgments}

This research was supported by the National Natural Science Foundation Fund (51874012), the National Key Research and Development Plan (2018YFC0808100), the Hebei Natural Science Foundation Fund (E2016209249), and the Graduate Student Innovation Fund of North China University of Science Technology (2018B26).

\section{References}

[1] W. Yang, B.-q. Lin, Y.-a. Qu et al., "Stress evolution with time and space during mining of a coal seam," International Journal of Rock Mechanics and Mining Sciences, vol. 48, no. 7, pp. 1145-1152, 2011.

[2] Y.-P. Cheng, L. Wang, and X.-L. Zhang, "Environmental impact of coal mine methane emissions and responding strategies in China," International Journal of Greenhouse Gas Control, vol. 5, no. 1, pp. 157-166, 2011.

[3] H. Zhou, J. Gao, K. Han, and Y. Cheng, "Permeability enhancements of borehole outburst cavitation in outburst-prone coal seams," International Journal of Rock Mechanics and Mining Sciences, vol. 111, pp. 12-20, 2018.

[4] D. Li, "A new technology for the drilling of long boreholes for gas drainage in a soft coal seam," Journal of Petroleum Science and Engineering, vol. 137, pp. 107-112, 2016.

[5] E. C. Dunlop, A. Salmachi, and P. J. McCabe, "Investigation of increasing hydraulic fracture conductivity within producing ultra-deep coal seams using time-lapse rate transient analysis: a long-term pilot experiment in the Cooper Basin, Australia," International Journal of Coal Geology, vol. 103, 2019.

[6] Y. Lu, L. Wang, Z. Ge, Z. Zhou, K. Deng, and S. Zuo, "Fracture and pore structure dynamic evolution of coals during hydraulic fracturing," Fuel, vol. 259, p. 116272, 2020.

[7] J. Xu, C. Zhai, L. Qin, and G. Yu, "Evaluation research of the fracturing capacity of non-explosive expansion material applied to coal-seam roof rock," International Journal of Rock Mechanics and Mining Sciences, vol. 94, pp. 103-111, 2017. 
[8] C. Zhai, J. Xu, S. Liu, and L. Qin, "Fracturing mechanism of coal-like rock specimens under the effect of non-explosive expansion," International Journal of Rock Mechanics and Mining Sciences, vol. 103, pp. 145-154, 2018.

[9] W. Nocuń-Wczelik, Z. Konik, and A. Stok, "Blended systems with calcium aluminate and calcium sulphate expansive additives," Construction and Building Materials, vol. 25, no. 2, pp. 939-943, 011.

[10] X. Li, Y. Zhang, X. Shen, Q. Wang, and Z. Pan, "Kinetics of calcium sulfoaluminate formation from tricalcium aluminate, calcium sulfate and calcium oxide," Cement and Concrete Research, vol. 55, pp. 79-87, 2014.

[11] K. Goto, K. Kojima, and K. Watabe, "The mechanism of expansive pressure and blowout of static demolition agent," in Proceedings of the Paper Presented at the Second International RILEM Symposium on Demolition and Reuse of Concrete and Masonry, Tokyo, Japan, November 1988.

[12] X. Liu, B. Ma, H. Tan et al., "Effect of aluminum sulfate on the hydration of Portland cement, tricalcium silicate and tricalcium aluminate," Construction and Building Materials, vol. 232, p. 117179, 2020.

[13] B. You, Static Blasting Technology: Silent Crushing Agent and its Application, China Building Materials Industry Press, Taiyuan, China, 2008.

[14] S. Arshadnejad, K. Goshtasbi, and J. Aghazadeh, "A model to determine hole spacing in the rock fracture process by nonexplosive expansion material," International Journal of Minerals, Metallurgy, and Materials, vol. 18, no. 5, pp. 509514, 2011.

[15] A. S. Natanzi, D. F. Laefer, and L. Connolly, "Cold and moderate ambient temperatures effects on expansive pressure development in soundless chemical demolition agents," Construction and Building Materials, vol. 110, pp. 117-127, 2016.

[16] W. Nocuń-Wczelik, A. Stok, and Z. Konik, "Heat evolution in hydrating expansive cement systems," Journal of Thermal Analysis and Calorimetry, vol. 101, pp. 527-532, 2010.

[17] S. Arshadnejad, "Design of hole pattern in static rock fracture process due to expansion pressure," International Journal of Rock Mechanics and Mining Sciences, vol. 123, p. 104100, 2019.

[18] V. R. S. De Silva, P. G. Ranjith, M. S. A. Perera, B. Wu, and T. D. Rathnaweera, "Investigation of the mechanical, microstructural and mineralogical morphology of soundless cracking demolition agents during the hydration process," Materials Characterization, vol. 130, pp. 9-24, 2017.

[19] S. P. Timoshenko and J. N. Goodier, Theory of Elasticity, McGraw Book Company, New York, NY, USA, 1951.

[20] A. Bentur and M. Ish-Shalom, "Properties of type K expensive cement of pure components II. Proposed mechanism of ettringite formation and expansion in unrestrained paste of pure expansive component," Cement and Concrete Research, vol. 4, no. 5, pp. 709-721, 1974.

[21] R. W. Hertzberg, Deformation and Fracture Mechanics of Engineering Materials, John Wiley \& Sons, New York, NY, USA, 1996.

[22] J. Hinze and J. Brown, "Properties of soundless chemical demolition agents," Journal of Construction Engineering and Management, vol. 120, no. 4, pp. 816-827, 1994.

[23] B. Kwiecińska, S. . Pusz, J. Brett, and Valentine, "Application of electron microscopy TEM and SEM for analysis of coals, organic-rich shales and carbonaceous matter," International Journal of Coal Geology, vol. 211, pp. 103-203, 2019.

[24] S.-B. Song, J.-F. Liu, D.-S. Yang et al., "Pore structure characterization and permeability prediction of coal samples based on SEM images," Journal of Natural Gas Science and Engineering, vol. 67, pp. 160-171, 2019.

[25] W. Zhang, Influence of Borehole Expansion Agent on Development Law of Coal Seam Fissure, North China University of Science and Technology, Habei, China, 2019. 